Article

\title{
Facile Fabrication of Hierarchical rGO/PANI@PtNi Nanocomposite via Microwave-Assisted Treatment for Non-Enzymatic Detection of Hydrogen Peroxide
}

\author{
Fa-Gui He ${ }^{1,2}$, Jia-Yi Yin ${ }^{1}$, Gaurav Sharma ${ }^{1,2}$, Amit Kumar ${ }^{1,2}$, Florian J. Stadler ${ }^{1}$ (D) \\ and Bing Du ${ }^{1, *(1)}$ \\ 1 College of Materials Science and Engineering, Shenzhen Key Laboratory of Polymer Science and Technology, \\ Guangdong Research Center for Interfacial Engineering of Functional Materials, Nanshan District Key Lab \\ for Biopolymers and Safety Evaluation, Shenzhen University, Shenzhen 518055, China \\ 2 Department of Optoelectronic Engineering, Shenzhen University, Shenzhen 518060, China \\ * Correspondence: dubing@szu.edu.cn
}

Received: 12 June 2019; Accepted: 30 July 2019; Published: 2 August 2019

check for updates

\begin{abstract}
A hierarchical composite based on the modified reduced graphene oxide with platinum-nickel decorated polyaniline nano-spheres (rGO/PANI@PtNi) was facilely prepared via microwave-assisted self-reduction for an application in nonenzymatic hydrogen peroxide $\left(\mathrm{H}_{2} \mathrm{O}_{2}\right)$ detection. Compared to the pristine rGO, the composite exhibited a much tougher surface due to the stacking of conductive PANI nano-spheres on rGO sheets, leading to good dispersion of PtNi nanoparticles and a large active area. Furthermore, the multi-valance $\mathrm{Ni}^{2+/ 3+}$ in the PtNi particles effectively promoted the catalytic property of Pt sites and facilitated a superior electrochemical performance of PtNi alloy than that of neat Pt. Owing to the synergistic effect of the improved electrical conductivity and the promoted electrocatalytical property, the modified glassy carbon electrode (GCE) with rGO/PANI@PtNi nanocomposite displayed an outstanding electrochemical sensitivity towards $\mathrm{H}_{2} \mathrm{O}_{2}$ with a fast response time $(<2 \mathrm{~s})$, a wide linear range $(0.1-126.4 \mathrm{mM})$, a low detection limit $(0.5 \mu \mathrm{M})$, as well as a long-life stability for one week without obvious degradation. This novel strategy opens a novel and promising approach to design high performance sensors for $\mathrm{H}_{2} \mathrm{O}_{2}$ detection.
\end{abstract}

Keywords: polyaniline; platinum-nickel nanoparticles; reduced graphene oxide; nonenzymatic detection; hydrogen peroxide

\section{Introduction}

Hydrogen peroxide $\left(\mathrm{H}_{2} \mathrm{O}_{2}\right)$ is one of the common bleaching or cleaning agents and a powerful oxidant that is widely used in many industrial processes [1-4]. Unfortunately, $\mathrm{H}_{2} \mathrm{O}_{2}$ also has very negative effects on the cell proliferation by triggering several kinds of essential signaling proteins, which leads to potentially serious diseases in our bodies, such as cancer, infarction, and atherosclerosis [5]. This renders it crucially important to accurately detect the concentration level of $\mathrm{H}_{2} \mathrm{O}_{2}$ in both natural and artificial surroundings. Among all the established technologies, the electrochemical detection is widely regarded as an effective and economical method owing to its simple instrumentation, rapid response, as well as its high sensitivity and selectivity [5-7]. In general, the electrochemical sensors for $\mathrm{H}_{2} \mathrm{O}_{2}$ determination are classified into enzymatic and non-enzymatic sensors according to their active components. Compared to the enzyme-based sensors, the non-enzymatic counterparts are identified to possess several noticeable advantages, such as better reproducibility and stability as well as higher and broader responsibility [8-10]. In the recent decades, considerable effort and attention 
have been devoted to developing the non-enzymatic modified electrode sensor systems for $\mathrm{H}_{2} \mathrm{O}_{2}$ detection [11-13].

As one typical catalyst, platinum $(\mathrm{Pt})$ presents excellent performance in many electrochemical reactions, including in the decomposition of $\mathrm{H}_{2} \mathrm{O}_{2}$ into aqua $\left(\mathrm{H}_{2} \mathrm{O}\right)$ and oxygen $\left(\mathrm{O}_{2}\right)$ [14]. Particularly, $\mathrm{Pt}$ can maintain its high activity in a neutral environment, which is favorable for the requested conditions of $\mathrm{H}_{2} \mathrm{O}_{2}$ detection [15]. Amatore's group microfabricated a platinum-black coated platinum (Pt/Pt-black) electrode that showed high sensitivity, allowing almost five decades of concentration with a detecting limitation down to $10 \mathrm{nM}$ [16]. In many recent works, several alloys based on Pt have been verified to possess even better performance than pristine $\mathrm{Pt}$ with improved catalytical activity, anti-interference, and long-term duration originating from the specific interaction in the alloys [17-20]. However, such nano-catalysts with extremely high surface energy cannot directly modify the electrode alone but have to be used with an essential support material to obtain satisfactory dispersibility and well-controlled particle size for sensing application. Among many possibilities, graphene oxide (GO) has been widely accepted as one extraordinary candidate for immobilizing the precursor of the catalysts owing to its substantial lattice defects and chemical groups [21]. Furthermore, the subsequent reduced graphene oxide ( $\mathrm{rGO}$ ) is a typical good conductor for electrochemical sensors with several superiorities, e.g., large surface area, excellent electron transport, as well as wide potential window [17,22-26]. To date, a good performance of the modified electrode on the basis of graphene and Pt-based catalyst composites has been reported in a great deal of literature [17,22,27-29].

However, there is still significant room for improvement in, for example, the aggregation for both graphene sheets and catalytic particles. To overcome this issue, the surfactants were introduced onto the graphene surfaces to counter the agglomeration and the hydrophobic properties of both graphene and metal-nanoparticles, such as cetyl trimethyl ammonium bromide (CTAB), sodium dodecyl benzyl sulfate (SDBS), and sodium dodecyl sulfate (SDS) [17,30-34]. These surfactants can not only contribute to perfecting the dispersion of the nano-components but can also facilitate the size construability of the catalysts due to the amplified active area for anchoring the metallic precursor or particles. Nonetheless, it is worth noting that most of the surface active agents for the graphene-based sensors reported thus far are insulating or semi-conductive in nature. Very recently, a few works started to use conductive polymers as the surfactant, expecting to achieve the improvement for both the dispersibility and the electrochemical properties. Qian et al. [35] loaded flow-like Au nano-particles (diameter $\approx 80 \mathrm{~nm}$ ) on polypyrrole/rGO (PPy/rGO) hybrid sheets via in-situ chemical oxidative polymerization. The modified glassy carbon electrode (GCE) based on this composite exhibited a good electrochemical performance for dopamine detection with remarkable sensitivity of $16.40 \mu \mathrm{A} / \mu \mathrm{M}$, low limitation of detection $(18.29 \mathrm{pM})$, and wide linear response range $(0.1-5000 \mathrm{nM})$. Zheng et al. [23] employed PANI nano-fibers with a diameter of 100-200 $\mathrm{nm}$ as the support for copper particles $(\mathrm{Cu})$ before depositing them on graphene sheets through sonication. In their case, the size of $\mathrm{Cu}$ nanoparticles was well controlled with a diameter of $2-4 \mathrm{~nm}$ in the presence of PANI fibers. Such size-controlled catalytic particles showed obvious contributions in the improved detecting behavior.

Herein, we fabricated a novel hierarchical nanocomposite combining stable aqueous polyaniline (PANI) nano-spheres and catalytical PtNi particles as well as rGO through a facile microwave treatment, which displayed a high sensitivity for quantitative $\mathrm{H}_{2} \mathrm{O}_{2}$ detection (Figure 1). PANI nano-spheres with an average diameter of $70 \mathrm{~nm}$ were employed for accelerating the electron transferring and also played as the surfactant in order to control the size of PtNi nanoparticles and improve the dispersibility of the PtNi particles. The catalytical nanoparticles were found to cover the PANI spheres without agglomeration. This unique morphology facilitated the interaction among all three active components and led to superior synergisms in the composite, allowing for improved electrochemical properties and superior detecting capability for $\mathrm{H}_{2} \mathrm{O}_{2}$. 


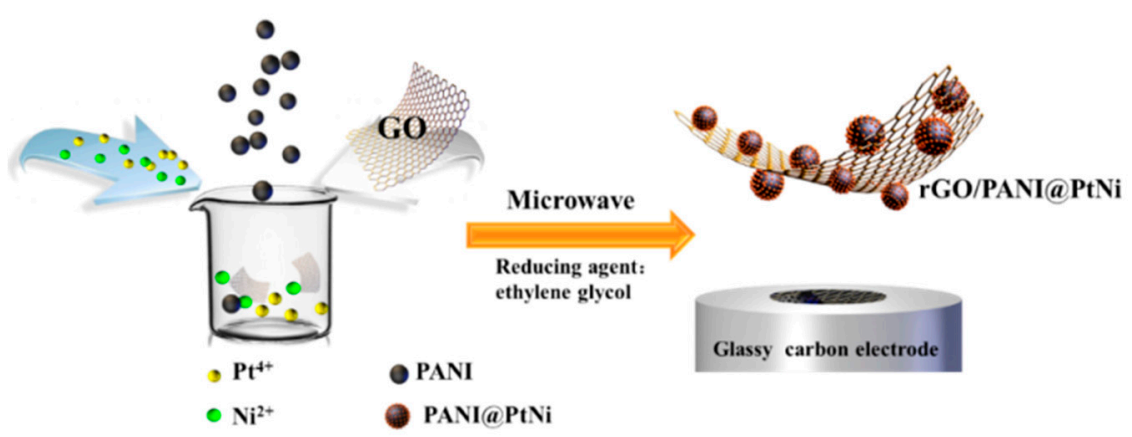

Figure 1. Scheme of fabricating the modified glassy carbon electrode (GCE) with platinum-nickel decorated polyaniline nano-spheres (rGO/PANI@PtNi) nanocomposite.

\section{Materials and Methods}

\subsection{Materials and Apparatus}

Graphene oxide (GO) was synthesized from pristine graphite (AlfaAesar, Tianjin, China) by following a modified Hummers method [36,37]. Polyvinyl alcohol (PVA, $M_{w}=27,000 \mathrm{~g} / \mathrm{mol}$, A.R., 99\%), ethylene glycol (EG, A.R., 98\%), ammonium persulphate (APS, A.R., 98.5\%), and hydrogen peroxide $\left(\mathrm{H}_{2} \mathrm{O}_{2}\right.$, A.R., 30 wt.\% in water) were obtained from Macklin Reagent Company (Shanghai, China). Chloroplatinic acid hexahydrate $\left(\mathrm{H}_{2} \mathrm{PtCl}_{6} \cdot 6 \mathrm{H}_{2} \mathrm{O}, 37.5 \mathrm{wt} . \% \mathrm{Pt}\right)$ was obtained from Sigma-Aldrich (St. Louis, MO, USA). Potassium phosphate monobasic $\left(\mathrm{KH}_{2} \mathrm{PO}_{4}\right.$, A.R., 99.5\%), sodium phosphate dibasic dodecahydrate $\left(\mathrm{Na}_{2} \mathrm{HPO}_{4} \cdot 12 \mathrm{H}_{2} \mathrm{O}\right.$, A.R., $\left.99 \%\right)$, potassium chloride ( $\mathrm{KCl}$, A.R., $\left.99.5 \%\right)$, and potassium ferricyanide $\left(\mathrm{K}_{3} \mathrm{Fe}(\mathrm{CN})_{6}\right.$, A.R., 99.5\%) were purchased from Aladdin Reagent Ltd. (Shanghai, China). $\mathrm{N}, \mathrm{N}$-dimethylformamide (DMF, A.R., $99 \%$ ) and nickel acetate tetrahydrate $\left(\mathrm{NiC}_{4} \mathrm{H}_{6} \mathrm{O}_{4} \cdot 4 \mathrm{H}_{2} \mathrm{O}\right.$, A.R., 99\%) were obtained from Shanghai Chemical Factory (Shanghai, China). All chemicals were used as received without further purification. The water used throughout all experiments was ultrapure water from a Millipore system. Phosphate buffer saline (PBS) was prepared by mixing stock solutions of $\mathrm{KH}_{2} \mathrm{PO}_{4}$ and $\mathrm{Na}_{2} \mathrm{HPO}_{4}$. A fresh solution of $\mathrm{H}_{2} \mathrm{O}_{2}$ was prepared daily.

The samples were characterized by scanning electron microscopy (SEM, SU-70, Hitachi, Japan), transmission electron microscopy (TEM, JEM-1230, Nippon Tekno, Japan), high-resolution transmission electron microscopy (HRTEM, HT-7700, Hitachi, Japan), X-Ray diffraction (XRD, D8 Avance, Bruker, Karlsruhe, Germany), in-situ X-ray photoelectron spectroscopy (in-situ XPS, PHI 5000 VersaProbe II, ULVAC-PHI, Japan), Fourier transform infrared spectroscopy (FT-IR, Nicolet 6700, Thermofisher Scientific, Waltham, MA, USA), and Raman spectroscope (inVia Raman Microscope, Renishaw, UK). The conductivity of PANI powder was tested with the ST2722-SZ four probe resistivity measuring instrument (Suzhou Jingge Electronic Co., Ltd., Suzhou, China). All electrochemical experiments were carried out at room temperature using an IVIUM electrochemical workstation (CompactStat.e 10800, Ivium Technology, Eindhoven, Netherlands) with a conventional three-electrode system. Bare or modified GCE, $\mathrm{Ag} / \mathrm{AgCl}$ electrode, and Pt wire were used as working electrode, reference electrode, and counter electrode, respectively. The interfacial charge transfer resistances for different modified surfaces were determined by electronic impedance spectroscopy (EIS) in the frequency range between $1 \mathrm{~Hz}$ and $1 \mathrm{MHz}$ with a perturbation signal of $5 \mathrm{mV}$. For current-time experiments, $4 \mu \mathrm{L}$ of Nafion $(0.5 \%)$ was additionally cast on the surface of the rGO/PANI@PtNi modified GC electrode and dried before electrochemical experiments.

\subsection{Synthesis of PANI Nano-Sphere}

First, $2 \mathrm{~mL}$ aniline was added into $10 \mathrm{~mL}$ PVA solution ( $5 \mathrm{wt} . \%$ in distilled water) under magnetic stirring at room temperature for $0.5 \mathrm{~h}$. Then, $2 \mathrm{~mL}$ of $\mathrm{HCl}$ solution $(2 \mathrm{M})$ was added into the system, and the brown suspension subsequently appeared. After $0.5 \mathrm{~h}, 8 \mathrm{~mL}$ of APS solution $(0.02 \mathrm{M})$ was added dropwise slowly, and then the system was under rigorous stirring for another $1 \mathrm{~h}$ at $5^{\circ} \mathrm{C}$. Afterwards, 
the suspension was kept at $4{ }^{\circ} \mathrm{C}$ for $24 \mathrm{~h}$; the resulting substance was collected by centrifugation (5000 rpm, $10 \mathrm{~min}$ ) and cleaned by repetitive washing with double-distilled water. Finally, the obtained PANI nanoparticles were purified by Soxhlet extraction and dried at $60^{\circ} \mathrm{C}$ in vacuo.

\subsection{Synthesis of rGO/PANI@PtNi Nanocomposite via Microwave Method}

In a typical synthesis, $2 \mathrm{~mL}$ of GO-water suspension $(2 \mathrm{mg} / \mathrm{mL})$ was added into $2 \mathrm{~mL}$ EG. Then, sequentially, $1 \mathrm{~mL}$ of $\mathrm{H}_{2} \mathrm{PtCl}_{6}$ EG solution $(77 \mathrm{mM}), 1 \mathrm{~mL}$ of $\mathrm{Ni}(\mathrm{CHCOO})_{2}$ EG solution $(228 \mathrm{mM})$, and $0.2 \mathrm{~mL}$ of PANI suspension (2 wt.\% in deionized (DI) water) were added. After being sonicated for $2 \mathrm{~min}$, the suspension was microwaved for $120 \mathrm{~s}$ (JOYN-H1C1 microwave oven, Shanghai Joyn Electronic Co., Ltd. China, power: $700 \mathrm{~W}$ ). The product was isolated by centrifugation at 10,000 rpm for $15 \mathrm{~min}$, followed by three washing/centrifugation cycles in water. The collected product was redispersed in $10 \mathrm{~mL}$ of ethanol by means of sonication, and colloidal suspension was obtained.

For better comparison, the individual components of this composite, namely neat rGO (the TEM image is shown in Supporting Information, Figure S1), platinum nanoparticles (the TEM image is shown in Figure S2), rGO/Pt (the TEM image is shown in Figure S3), rGO/PtNi (the TEM image is shown in Figure S4), and rGO/Pt/PANI (the SEM images are shown in Figure S5) were also prepared through almost the same process but without the addition of rGO, PANI, or without both PANI and metallic precursors.

\subsection{Preparation of Modified GCE Electrode}

The GCE (a disk with a diameter of $3 \mathrm{~mm}$ ) was polished with 1, 0.5, and $0.3 \mathrm{~mm}$ alumina powder, respectively and then successively rinsed by sonication with ethanol and deionized water. The polished GCE was allowed to dry under a gentle nitrogen stream before use. Then, the modified GCE was fabricated by a simple casting method of dropping $5 \mu \mathrm{L}$ of rGO/PANI@PtNi suspension $(0.1 \mathrm{mg} / \mathrm{mL}$, dispersed in ethanol) onto the cleaned GCE surface. The electrode was dried in the atmosphere before further characterization.

To be compared, rGO/GCE, Pt/GCE, rGO/Pt/GCE, rGO/PtNi/GCE, and rGO/ PANI@Pt/GCE electrodes were prepared through the same procedure.

\section{Results}

\subsection{Characterization of PANI Nano-Spheres}

It is known that PANI is an excellent conductive polymer and is widely used for electrochemical applications. However, the poor water dispersibility of PANI hampers its processability and performance. Introducing a water soluble polymer as a support during the polymerization is considered to be an effective solution to improve water dispersibility and mechanical properties of PANI [38,39]. In this work, we synthesized proton acid doped polyaniline hybrid in the presence of water soluble PVA as the support. As a reference, the pristine PANI was also prepared without PVA. As shown in Figure 2, PANI with PVA support maintained good dispersibility in water, even after standing for $12 \mathrm{~h}$, while the pristine PANI started to aggregate just after $10 \mathrm{~min}$ and absolutely formed sediment after $12 \mathrm{~h}$. Apparently, using PVA support can efficiently improve the dispersibility of PANI, which is expected to be beneficial to achieve good homogeneity for the ultimate composites. 


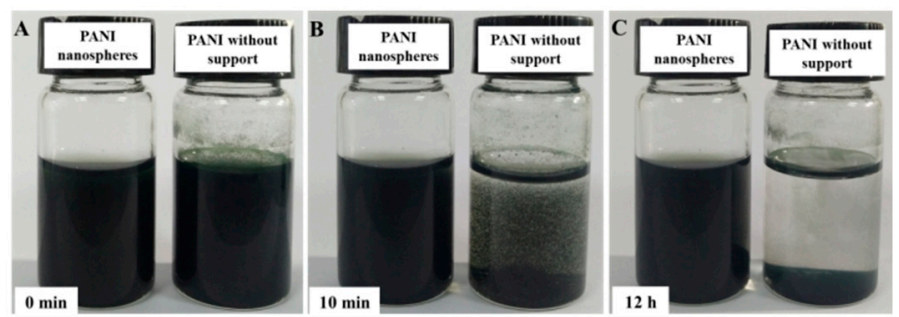

Figure 2. Photographs of aqueous PANI and pristine polyaniline dispersion ( $15 \mathrm{~mL}, 0.2 \mathrm{mg} / \mathrm{mL})$ : as ultra-sonicated (A); after leaving it undisturbed for $10 \mathrm{~min}$ (B); after leaving it undisturbed for $12 \mathrm{~h}(\mathbf{C})$.

The chemical structure of as-synthesized PANI was identified by FT-IR spectrum (Figure S6). The bands located at $3406 \mathrm{~cm}^{-1}$ and $1289 \mathrm{~cm}^{-1}$ corresponded to the stretching vibrations of $\mathrm{N}-\mathrm{H}$ and $\mathrm{C}-\mathrm{N}$, respectively [40-44]. The appearance of these bands indicated the existence of the amide group from PANI $[40,44,45]$. Importantly, another strong band at $1122 \mathrm{~cm}^{-1}$ was associated with a high degree of electron delocalization and transfer in PANI, illustrating that the as-synthesized PANI was in the protonated emeraldine (EM) state [41,46-49]. This result was in accordance with the electrical conductivity of $4.9 \mathrm{~s} / \mathrm{cm}$ for the received PANI powder determined by a standard four-probe technique.

\subsection{Morphology and Structure of the Composites}

Figure 3 gives the SEM images of rGO/PtNi and rGO/PANI@PtNi, respectively. rGO/PtNi exhibited as a flat-sheet, where the surface was a bit wrinkled and crumpled. The roughness of the surface was likely attributed to the stacking of ultrathin graphene sheets in the dry state and the coating layer consisting of PtNi particles (Figure 3A). On the other hand, the presence of PANI led to a significantly rougher surface formed by the stacked PANI nano-spheres (an average diameter of $70 \mathrm{~nm}$ ) on the rGO surface in both rGO/PANI@PtNi and rGO/PANI composites (Figure 3B and Figure S7).
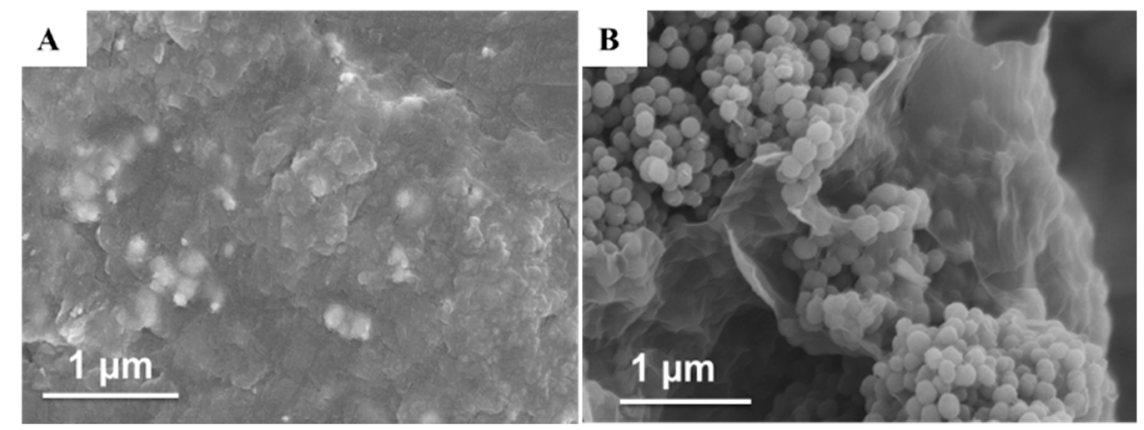

Figure 3. SEM images of rGO/PtNi (A) and rGO/PANI@PtNi (B).

The distribution of PtNi particles in rGO/PANI@PtNi were examined by high revolution transmission electron microscope (HRTEM). Figure 4 indicates that the vast majority of the PtNi particles thoroughly wrapped the PANI spheres monodispersely. This selective location of the metallic particles could be attributed to the stronger attraction from amine groups to the metallic ions than the one from hydroxyl and carboxyl groups on the rGO surface [50]. The d values for the metal crystal plane (111) were estimated with a value of $0.225 \mathrm{~nm}$, which was slightly smaller than the one of pristine $\mathrm{Pt}(111)$ crystal planes $(0.227 \mathrm{~nm})$ [51,52]. On the other hand, the $\mathrm{d}$ spacing for (200) was $0.192 \mathrm{~nm}$, which could be assigned to the (200) plane of Pt3Ni alloy $(0.191 \mathrm{~nm})$ [53]. Considering this crystallographic plane, it might conclude an alloy formation between Pt and Ni on the PANI surface after microwave reduction. Additionally, the presence of PANI was also found to be beneficial to control the particle size. The average diameter of PtNi was sharply reduced from $8.1 \mathrm{~nm}$ for $\mathrm{rGO} / \mathrm{PtNi}$ to $1.7 \mathrm{~nm}$ for $\mathrm{rGO} / \mathrm{PANI} @ \mathrm{PtNi}$ with an apparently narrower distribution (Figure S8). This superior dispersibility on PANI and well-controlled particle size of PtNi particles could have arisen from the 
tremendously large active area for anchoring the metallic precursors, which was provided by the well-stacked PANI-nanoparticles with a small average diameter of only $70 \mathrm{~nm}$.
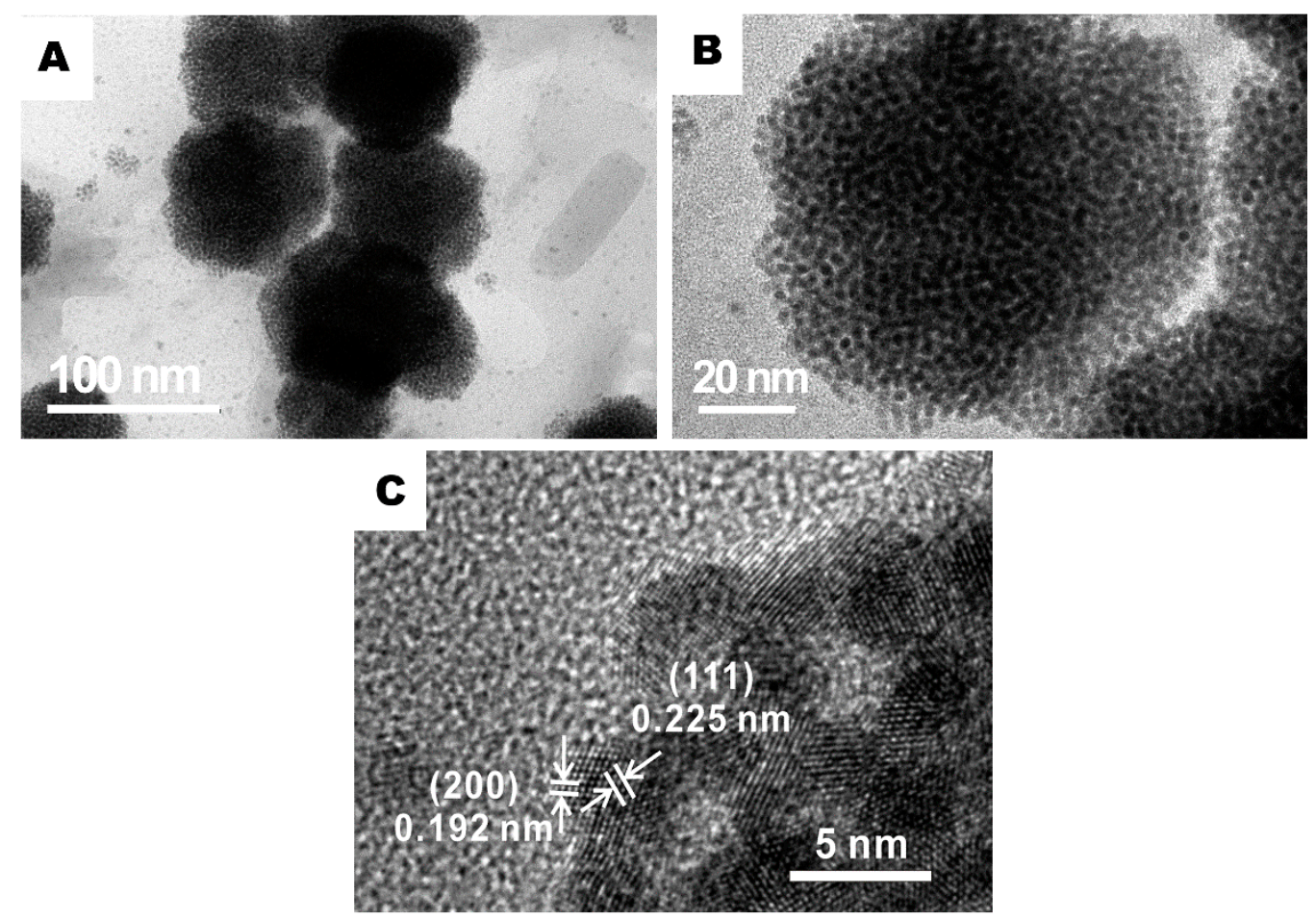

Figure 4. Representative high revolution transmission electron microscope (HRTEM) images of the rGO/PANI@PtNi composite at various magnifications: (a) $\times 75,000 ;(\mathbf{b}) \times 195,000 ;(\mathbf{c}) \times 1,000,000$

To further understand the structure of the composites, rGO/PANI@PtNi was further characterized by XRD (Figure 5A), Raman spectroscopy (Figure 5B), as well as XPS (Figure 5C-F). The XRD pattern of GO exhibited the strong (001) peak at $11.3^{\circ}$, while it vanished in the spectrum of the rGO/PANI@PtNi sample, confirming successful reduction of GO after the microwave treatment $[5,54]$. Moreover, the presence of PANI@PtNi nano-spheres was found to serve as spacers to prevent the graphene sheets from restacking due to van der Waals interactions. Therefore, the increased interlayer between the rGO sheets was another factor leading to the disappearance of the (001) rGO diffraction peak [5,55]. The peaks at $39.9^{\circ}, 46.3^{\circ}, 67.8^{\circ}$, and $81.5^{\circ}$ of the rGO/PANI@PtNi composite could be assigned to (111), (200), (220), and (311) of fcc structured Pt nanocrystals, respectively [56]. However, there were no characteristic peaks of $\mathrm{Ni}$ or its oxides/hydroxides detected in the composites. This could be explained by the formation of alloy between $\mathrm{Pt}$ and $\mathrm{Ni}$, since $\mathrm{Pt}$ is known to be alloyed well with $\mathrm{Ni}$ [57]. Furthermore, the $2 \theta$ value of the (111) peak in the case of rGO/PANI@PtNi (39.9 ${ }^{\circ}$ ) exhibited a higher angle shift than that of the rGO/PANI@Pt without $\mathrm{Ni}\left(39.7^{\circ}\right)$, which also accounted for the alloy of $\mathrm{Pt}$ and $\mathrm{Ni}$ [51,58-60]. Thus, XRD results were in good accordance with the crystallographic plane presented in HRTEM results and verified the successful alloy formation of PtNi in the composite. 

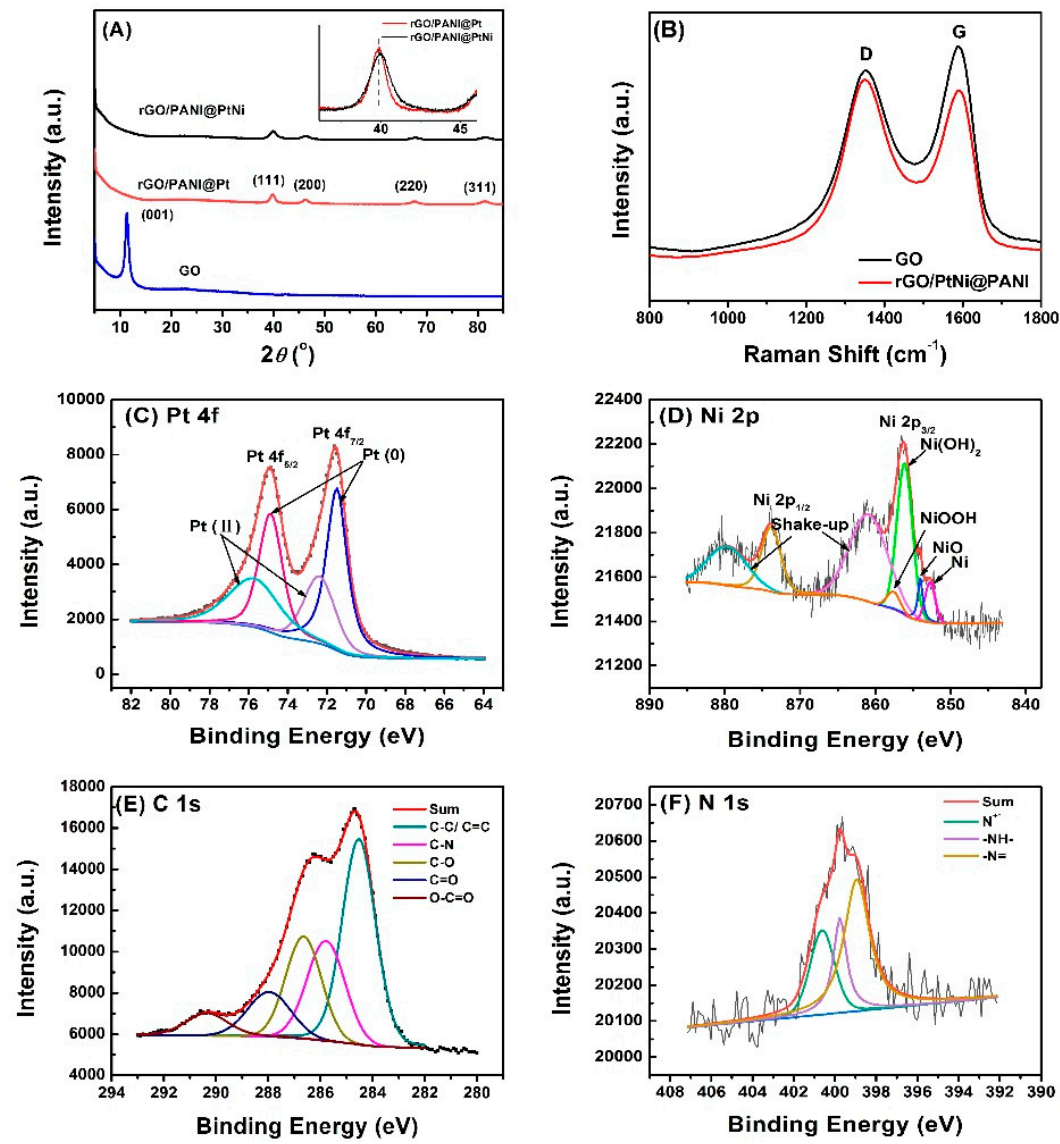

Figure 5. XRD patterns of the as-synthesized GO,rGO/PANI@PtNi, and rGO/PANI@Pt. Inset: the amplified plots of (111) peaks for rGO/PANI@PtNi and rGO/PANI@Pt (A); Raman spectroscopy of GO and rGO/PtNi@PANI nanocomposite (B); X-ray photoelectron spectroscopy (XPS) of Pt 4f (C), Ni 2p (D), C 1s (E), and N 1s (F) for the rGO/PANI@PtNi composite.

The reduction of GO into rGO through microwave treatment was further identified by comparing Raman spectrum of GO and rGO/PANI@PtNi (Figure 5B). Both of the curves showed obvious peaks at $\sim 1350 \mathrm{~cm}^{-1}$ and $1589 \mathrm{~cm}^{-1}$, corresponding to the $\mathrm{D}$ band and the $\mathrm{G}$ band, respectively. The $\mathrm{D}$ band was attributed to the disorder and the imperfection of the carbon crystallites, while the $G$ band originated from the in-plane bond-stretching vibration of $\mathrm{sp} 2$ bonded. Thus, the intensity ratio of the $\mathrm{D} / \mathrm{G}$ bands $\left(\mathrm{I}_{\mathrm{D}} / \mathrm{I}_{\mathrm{G}}\right)$ reflected the extent of $\mathrm{sp} 2$ domains and structural disorder of graphene sheets. In this work, although the rGO/PANI@PtNi composite was prepared via a reduction processing, its $\mathrm{I}_{\mathrm{D}} / \mathrm{I}_{\mathrm{G}}(0.71)$ was almost two times that of the ratio of GO (1.44), illustrating the decreased in-plane $\mathrm{sp}^{2}$ domains and a partially ordered crystal structure of the reduced sheets. This relatively high $\mathrm{I}_{\mathrm{D}} / \mathrm{I}_{\mathrm{G}}$ in $\mathrm{rGO} / \mathrm{PANI} @ \mathrm{PtNi}$ was in good accordance with the results reported in literature about rGO composites and could be explained by the limited size of the reestablished rGO network ( $\mathrm{sp}^{2}$ carbon) relative to the original ones, as well as the interactions among the graphene, the PANI, and the PtNi [22,25,28].

The chemical states of rGO/PANI@PtNi composites were detected by XPS that clearly demonstrated the synergic combination of all three components (Figure S9). The fitted spectra of $\mathrm{Pt} 4 \mathrm{f}, \mathrm{N} \mathrm{2p}, \mathrm{C} 1 \mathrm{~s}$, and $\mathrm{N}$ 1s are shown in Figure 5C-F, respectively. In the spectrum of $\mathrm{Pt} 4 \mathrm{f}$, the peaks with binding energies at $71.49 \mathrm{eV}$ and $74.87 \mathrm{eV}$ for $\mathrm{Pt}(0)\left(\mathrm{Pt}_{4} \mathrm{f}_{7 / 2}\right.$ and $\left.\mathrm{Pt} 4 \mathrm{f}_{5 / 2}\right)$ and $72.38 \mathrm{eV}$ and $75.8 \mathrm{eV}$ for $\mathrm{Pt}$ (II) $\left(\mathrm{Pt} 4 \mathrm{f}_{7 / 2}\right.$ and $\left.\mathrm{Pt} 4 \mathrm{f}_{5 / 2}\right)$ were detected, respectively. The content of $\mathrm{Pt}(0)(60 \%)$ was higher than that of $\mathrm{Pt}$ (II) (40\%). Moreover, with the reference to rGO/PANI@Pt, the Pt $4 \mathrm{f}_{7 / 2}$ and the Pt $4 \mathrm{f}_{5 / 2}$ peaks of rGO/PANI@PtNi displayed a very obvious shift from $72.73 \mathrm{eV}$ and $75.97 \mathrm{eV}$ for rGO/PANI@Pt to 72.43 and $75.72 \mathrm{eV}$ for rGO/PANI@PtNi (Figure S10), which was ascribed to the electron donating from Ni sites occurring in the PtNi alloy $[56,60]$. On the other hand, the Ni 2p spectrum indicated the existence 
of metallic oxides and hydroxide rather than $\mathrm{Ni}(0)$ state, which was found to be universal in the case of PtNi alloys [56,61,62]. In detail, the Ni 2 $\mathrm{p}_{3 / 2}$ XPS at the binding energies of $853.4 \mathrm{eV}, 856.2 \mathrm{eV}$, and $857.3 \mathrm{eV}$ were supposed to be assigned to $\mathrm{NiO}, \mathrm{Ni}(\mathrm{OH})_{2}$, and $\mathrm{NiOOH}$, respectively [60]. These XPS results for the amorphous $\mathrm{Ni}$ could well explain that peaks of Ni were not detected in XRD spectrum of rGO/PANI@PtNi (Figure 5A). Besides, the maintenance of the doped state for PANI spheres was also detected by the peak at the binding energy higher than $400 \mathrm{eV}(400.6 \mathrm{eV})$ in the curve-fitted $\mathrm{N} 1 \mathrm{~s}$ spectrum (Figure 5F), which was very essential for the composite to acquire good conductivity [63]. From the above results of XRD, XPS, and Raman, it could be concluded that the reduction of GO and the formation of PtNi alloy with hydrogen groups successfully occurred via the microwave fabrication in the case of rGO/PANI@PtNi, which were expected to facilitate the electrochemical performance of the rGO/PANI@PtNi composite in view of its potential superiority in electrical conductivity and catalysis.

\subsection{Electrochemical Properties of the Modified GCE}

The conductivities of the different electrodes were characterized by carrying out the cyclic voltammetry $(\mathrm{CV})$ on the different electrodes in $0.1 \mathrm{M} \mathrm{KCl}$ solution containing $5.0 \mathrm{mM} \mathrm{K}_{3} \mathrm{Fe}(\mathrm{CN})_{6}{ }^{3-}$. As shown in Figure 6A, a typical quasi-reversible one-electron redox behavior of ferricyanide ions was observed in the curves of all the electrodes. The influence of each component on the electro-conductivity of the composites was investigated through comparing the peak current and the average electroactive surface area of the different electrodes (Table 1). The average electroactive surface area $(A)$ was estimated based on the Randles-Sevcik equation [64]:

$$
I_{p}=2.69 \times 10^{5} \times A \times D^{\frac{1}{2}} \times n^{\frac{2}{3}} \times \gamma^{\frac{1}{2}} \times C
$$

where $I p$ is the redox peak current, $A$ relates to the area of the electroactive surface area $\left(\mathrm{cm}^{2}\right)$, the diffusion coefficient of the molecule in solution $(D)$ is $6.70 \pm 0.02 \times 10^{-6} \mathrm{~cm}^{2} \mathrm{~s}^{-1}, n$ is the number of electrons participating in the redox reaction ( $n=1$ in case of one-electrode here), $\gamma$ is the scan rate of the potential perturbation $\left(0.05 \mathrm{~V} \mathrm{~s}^{-1}\right)$, and $C$ corresponds to the bulk concentration of the redox probe ( $5 \mathrm{mM}$ ). With reference to the bare GCE, the modification of GCE with rGO exhibited a very limited improvement on the conductivity only with an increase of $5.7 \mu \mathrm{A}$. After Pt particles were loaded on the rGO surface, the peak current of the $\mathrm{rGO} / \mathrm{Pt}$ significantly increased; meanwhile, $\Delta E_{p}$ became $23 \mathrm{mV}$ smaller than the one of $\mathrm{rGO} / \mathrm{GCE}$, indicating the importance of $\mathrm{Pt}$ to improve the conductivity of the graphene materials. Moreover, PANI was also found to further facilitate the improvement of the conductivity with the increase of anode current both from $58.3 \mu \mathrm{A}$ for $\mathrm{rGO} / \mathrm{Pt}$ to $67.4 \mu \mathrm{A}$ for rGO/PANI@Pt and from $62.0 \mu \mathrm{A}$ for rGO/PtNi to $72.4 \mu \mathrm{A}$ for rGO/PANI@PtNi. With PANI spheres, the electroactive surface area could be increased for more than $0.012 \mathrm{~cm}^{2}$. Importantly, the electroactive surface area of rGO/PANI@PtNi was 4.8 times that of bare GCE and 3.4 times that of pristine rGO. However, we also noticed that the enhancement resulting from the addition of $\mathrm{Ni}$ was very slight (less than $10 \mu \mathrm{A}$ ) as compared with the effects of Pt and rGO, which could be explained by the amorphous state of $\mathrm{Ni}$ in the PtNi alloy. Thus, we strongly suggest that Pt and PANI were supposed to display the predominant contribution to the promotion of the electrical conductivity for the rGO/PANI@PtNi composite rather than the Ni. The results from EIS (Figure 6B) were in good accordance with this conclusion with an electron transfer resistance $\left(R_{c t}\right)$ in sequence of: $R_{c t-b a r e}>R_{c t-r G O}>R_{c t-P t}>R_{c t-r G O / P t}>$ $R_{c t-r G O / P t N i}>R_{c t-r G O / P A N I @ P t}>R_{c t-r G O / P A N I @ P t N i}$. 

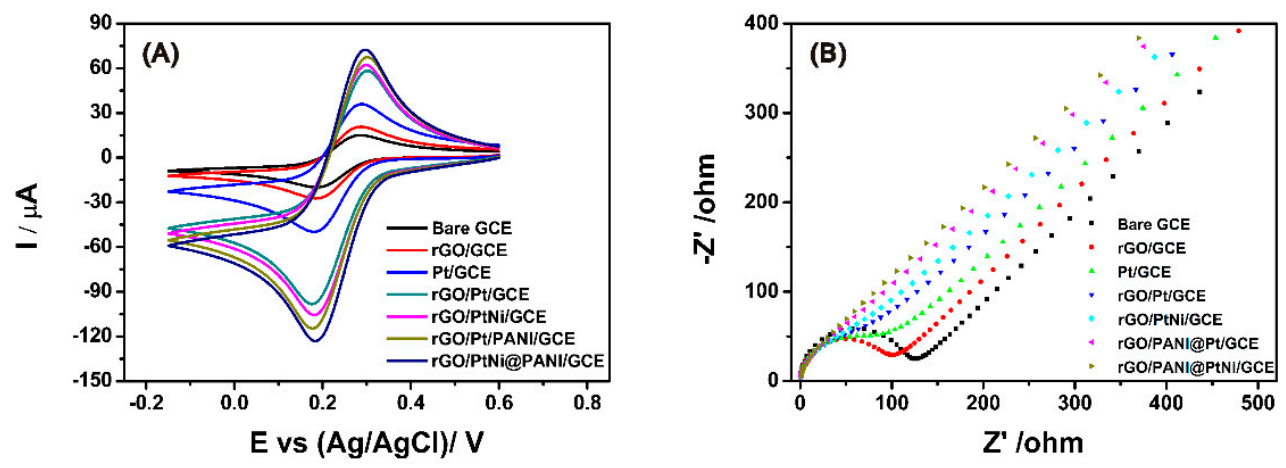

Figure 6. Cyclic voltammetry (CV) of bare GCE, rGO/GCE, Pt/GCE, rGO/Pt/GCE, rGO/PtNi/GCE, rGO/PANI@Pt/GCE and rGO/PANI@PtNi/GCE rGO/PtNi/GCE, rGO/PANI@Pt/GCE and rGO/PANI@PtNi/GCE in $0.1 \mathrm{M} \mathrm{KCl}$ containing $5.0 \mathrm{mM} \mathrm{Fe}(\mathrm{CN})_{6}{ }^{3-}$ at the scan rate of $50 \mathrm{mV} / \mathrm{s}(\mathrm{A})$; electronic impedance spectroscopy (EIS) spectra obtained at bare GCE, rGO/GCE, Pt/GCE, rGO/Pt/GCE, rGO/PtNi/GCE, rGO/PANI@Pt/GCE and rGO/PANI@PtNi/GCE in $0.1 \mathrm{M} \mathrm{KCl} \mathrm{containing} 5.0 \mathrm{mM}$ $\mathrm{Fe}(\mathrm{CN})_{6}^{3-/ 4-}(\mathbf{B})$.

Table 1. The anodic peak current and the average electroactive surface area of PtNi on different electrodes.

\begin{tabular}{ccc}
\hline Electrode & Anodic Peak Current $(\boldsymbol{\mu A})$ & $\begin{array}{c}\text { Average Electroactive Surface } \\
\text { Area * }(\mathbf{A})\left(\mathbf{c m}^{\mathbf{2}}\right)\end{array}$ \\
\hline Bare GCE & 15.0 & 0.019 \\
rGO/GCE & 20.7 & 0.027 \\
Pt/GCE & 35.8 & 0.046 \\
rGO/Pt/GCE & 58.3 & 0.075 \\
rGO/PtNi/GCE & 62.0 & 0.079 \\
rGO/PANI@Pt/GCE & 67.4 & 0.087 \\
rGO/PANI@PtNi/GCE & 72.4 & 0.093
\end{tabular}

* Average electroactive surface area was calculated based on the Equation (1), as discussed above. The geometry of the bare electrode was a disk with a diameter of $3 \mathrm{~mm}$ (the geometric area was $0.071 \mathrm{~cm}^{-2}$ ).

\subsection{Sensing Performance of the Modified Electrodes for $\mathrm{H}_{2} \mathrm{O}_{2}$ Detection}

The amperometric response of the modified GCE for $\mathrm{H}_{2} \mathrm{O}_{2}$ was determined in $0.2 \mathrm{M} \mathrm{N}_{2}$-saturated PBS solution containing $0.1 \mathrm{mM} \mathrm{H}_{2} \mathrm{O}_{2}$ at a scan rate of $50 \mathrm{mV} / \mathrm{s}$ with a successive addition of $\mathrm{H}_{2} \mathrm{O}_{2}$. In order to acquire efficient sensitivity and quantitative electrochemical detection, the $\mathrm{pH}$ value for testing was optimized by characterizing the sensing performance of the rGO/PANI@PtNi/GEC in the test solution with various $\mathrm{pH}$ values (Figure S11). Based on the resultant curves, an optimal solution $\mathrm{pH}$ of 6.5 was detected in view of its highest peak current, which was applied in the following electrochemical characterizations.

Figure 7 gives the cyclic voltammograms of bare GCE, rGO/PtNi/GCE, rGO/Pt/PANI/GCE, and $\mathrm{rGO} / \mathrm{PANI} @ \mathrm{PtNi} / \mathrm{GCE}$ being detected at $\mathrm{pH}=6.5$. In the case of the bare GCE, both the oxidation and the reduction peaks were barely visible, which could be explained by the extremely slow reaction process occurring on the electrode without any modification. Similar to the previous study of the composite sensor based on rGO and Pt particles [28,65], a reduction peak could be distinctly observed in the potential window $(-0.8 \mathrm{~V}$ to $2.0 \mathrm{~V})$ for all the electrodes containing $\mathrm{Pt}$ sites, while no oxidation peak appeared in the reverse potential scan. Thus, it could be concluded that the $\mathrm{H}_{2} \mathrm{O}_{2}$ detection on the modified electrodes underwent an irreversible reduction process. Among the modified electrodes, the rGO/PANI@PtNi/GCE displayed the highest current response and also the most positive reduction potential, illustrating its outstanding electronic transfer for the $\mathrm{H}_{2} \mathrm{O}_{2}$ testing. Comparing the response of $\mathrm{rGO} / \mathrm{PANI} @ \mathrm{PtNi} / \mathrm{GCE}$ with the one of $\mathrm{rGO} / \mathrm{PtNi} / \mathrm{GCE}$, PANI nano-spheres showed noteworthy effects in increasing the cathodic peak current for the $\mathrm{H}_{2} \mathrm{O}_{2}$ testing system from $39.2 \mu \mathrm{A}$ for $\mathrm{rGO} / \mathrm{PtNi} / \mathrm{GCE}$ 
to $59.0 \mu \mathrm{A}$ for rGO/PANI@PtNi/GCE, which was in accordance with the conductivity tested in the $\left[\mathrm{Fe}(\mathrm{CN})_{6}{ }^{3-}\right]$ solution discussed before. Furthermore, it was also interesting to note that the addition of Ni led to a relatively higher amplification of current response of $11.8 \mu \mathrm{A}$ from GO/PANI@Pt/GCE to rGO/PANI@PtNi/GCE.

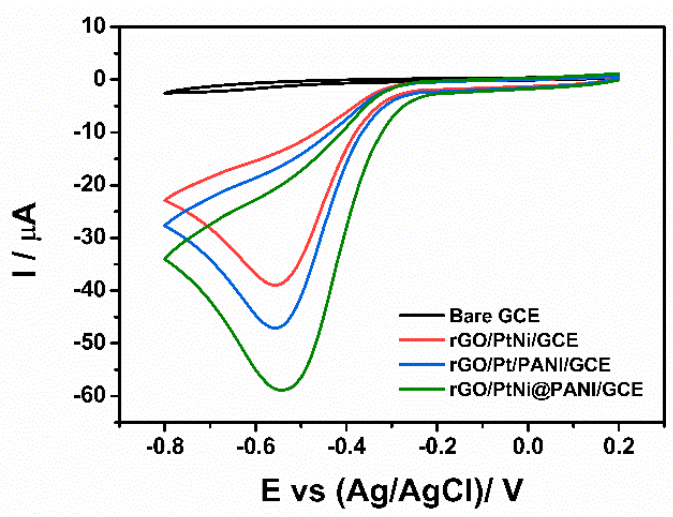

Figure 7. CVs of bare GCE, rGO/PtNi/GCE, rGO/Pt/PANI/GCE, and rGO/PANI@PtNi/GCE in $\mathrm{N}_{2}$-saturated 0.2 M phosphate buffered saline (PBS) at $\mathrm{pH}$ : 6.5 in the presence of $0.1 \mathrm{mM} \mathrm{H}_{2} \mathrm{O}_{2}$ (scan rate: $50 \mathrm{mV} / \mathrm{s}$ ).

These results could be explained by the facilitation from $\mathrm{Ni}$ hydroxides for the electrocatalytic property of Pt. Based on the previous systematical studies about the mechanism of $\mathrm{H}_{2} \mathrm{O}_{2}$ electrochemistry on $\mathrm{Pt}$ particles [66,67], the electrochemical decomposition $\mathrm{of}_{2} \mathrm{H}_{2}$ on $\mathrm{Pt}$ firstly started with the dissociation of $\mathrm{H}_{2} \mathrm{O}_{2}$ into $\mathrm{OH}$ groups followed by absorbing on at least two $\mathrm{Pt}$ sites' surfaces:

$$
\mathrm{Pt}+\mathrm{H}_{2} \mathrm{O}_{2} \rightarrow 2 \mathrm{Pt}(\mathrm{OH})
$$

Then, an electrochemical reduction of the resultant $\mathrm{Pt}(\mathrm{OH})$ subsequently occurred, being initiated by the instable absorbed $\mathrm{OH}$ on the Pt sites:

$$
4 \mathrm{Pt}(\mathrm{OH}) \stackrel{e^{-}}{\rightarrow} 4 \mathrm{Pt}+2 \mathrm{H}_{2} \mathrm{O}+\mathrm{O}_{2}
$$

Owing to this regeneration, the free Pt sites were formed again and available for the next dissociation of other $\mathrm{H}_{2} \mathrm{O}_{2}$. From XPS spectrum of Ni 2p for rGO/PANI@PtNi (Figure 5D), it was suggested that the surface layer of $\mathrm{PtNi}$ alloy contained both $\mathrm{Ni}(\mathrm{OH})$ and $\mathrm{NiOOH}$. In several former works $[60,61,68,69]$, such mixed-valence $\mathrm{Ni}^{2+} / \mathrm{Ni}^{3+}$ has been demonstrated to be advantageous to improve the conductivity and the catalytic activity through the following electrochemical reversible reaction:

$$
\mathrm{Ni}(\mathrm{OH})_{2} \leftrightarrow \mathrm{NiOOH}+\mathrm{H}^{+}+\mathrm{e}^{-}
$$

Thus, forming alloy with Ni could effectively promote the catalytical efficiency of Pt sites with high current response for $\mathrm{H}_{2} \mathrm{O}_{2}$. Considering the above electrochemical characterizations, we deemed that the facilitated electrochemical sensitivity of rGO/PANI@PtNi for $\mathrm{H}_{2} \mathrm{O}_{2}$ was attributed to two synergistic factors (Figure 8). First, the good stacking of the doped-PANI nano-spheres on the rGO surface could be beneficial to improving the electronic conductivity in the system, not only resulting from their own superior conductivity but also from the sophisticated structure they formed with a large active area for both electronic transfer and absorption of the catalyst. Second, the existence of $\mathrm{Ni}$ in the PtNi alloy efficiently facilitated the electrocatalytic performance of the composite by promoting the electrochemical reduction of the regeneration of $\mathrm{Pt}$ sites during the $\mathrm{H}_{2} \mathrm{O}_{2}$ decomposition. 


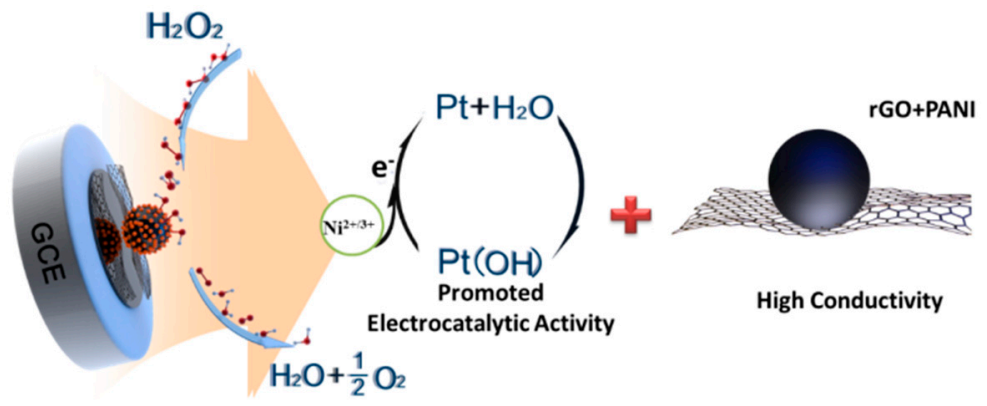

Figure 8. Scheme of the mechanism of $\mathrm{H}_{2} \mathrm{O}_{2}$ decomposition on rGO/PANI@PtNi/GCE.

Figure 9A shows a typical current-time plot of the rGO/PANI@PtNi modified GCE for $\mathrm{H}_{2} \mathrm{O}_{2}$ detection by successively adding $\mathrm{H}_{2} \mathrm{O}_{2}$ into the stirring PBS $(\mathrm{pH}=6.5)$ under an applied voltage of $0 \mathrm{~V}$. It clearly reveals that the current response increased with the concentration of $\mathrm{H}_{2} \mathrm{O}_{2}$, and the sensor rapidly achieved $96 \%$ of the steady state current in $2 \mathrm{~s}$. The sensitivity of rGO/PANI@PtNi was further characterized by studying the calibration plot of the sensor, as shown in Figure 9B. The linear detection range was estimated to be from $0.1 \mathrm{mM}$ to $126 \mathrm{mM}\left(\mathrm{R}^{2}=0.9989\right)$, and the detection limit was estimated to be $0.5 \mu \mathrm{M}$ on the basis of $\mathrm{S} / \mathrm{N}=3$ [22,70]. This detection limitation was much lower than that of the rGO/PANI@Pt/GCE $(1.1 \mu \mathrm{M})$ without the addition of Ni (Figure S12), which further confirmed the positive effect of $\mathrm{Ni}$ sites on facilitating the electrocatalytic performance. The sensitivity and the detection limit of rGO/PANI@PtNi/GCE showed favorable and competitive electrocatalytic performance compared to that of some previously reported sensors based on graphene sheets (Table 2). It could therefore be suggested that $\mathrm{rGO} / \mathrm{PANI} @ \mathrm{PtNi} / \mathrm{GCE}$ possessed a superior sensitivity for $\mathrm{H}_{2} \mathrm{O}_{2}$ detection, which could be attributed to a synergistic effect combining the improved electron transfer and the promoted electrocatalytic property as well as the large active area originating from the good assembly of PANI nano-spheres on rGO sheets.

Table 2. Comparison of the electrochemical performance of $\mathrm{H}_{2} \mathrm{O}_{2}$ sensors based on the graphene composites.

\begin{tabular}{ccccc}
\hline Material & $\begin{array}{c}\text { Applied } \\
\text { Potential }(\mathbf{V})\end{array}$ & $\begin{array}{c}\text { Linear Range } \\
(\mu \mathbf{M})\end{array}$ & LOD $(\boldsymbol{\mu M})$ & Ref \\
\hline Graphene-Pt & 0 & $2-710$ & 0.5 & {$[71]$} \\
Catalase/Porous Graphene & -0.35 & $0.1-7.7$ & 0.083 & {$[72]$} \\
Graphene-CNT-Pt & -0.005 & $0.1-25$ & 0.01 & {$[73]$} \\
PtNPs/Graphene paper & -0.25 & $0.2-2000$ & 0.1 & {$[74]$} \\
$\mathrm{Fe}_{3} \mathrm{O}_{4} @$ PANI/rGO & -0.9 & $100-1500$ & 4.45 & {$[75]$} \\
AgNPs/N-doped graphene & -0.3 & $100-126,400$ & 1200 & {$[5]$} \\
RGO/nAPAMSs & -0.5 & $5-4000$ & 0.008 & {$[76]$} \\
(AuPt alloy) & -0.45 & $2-19,500$ & 0.7 & {$[77]$} \\
$\mathrm{Nf} / \mathrm{Pd@Ag/rGO-NH} / \mathrm{GCE}$ & -0.3 & $100-260,000$ & 4 & {$[78]$} \\
$\mathrm{Ag} / \mathrm{F}-\mathrm{SiO} / \mathrm{GO}$ & -0.1 & $0.8-12,780$ & 0.5 & {$[79]$} \\
$\mathrm{Cu} \mathbf{H}_{2} \mathrm{O} / \mathrm{PANI} / \mathrm{rGO}$ & -0.25 & $20-8000$ & 1.7 & {$[80]$} \\
$\mathrm{Au}-\mathrm{graphene-HRP-chitosan}$ & -0.1 & $1-30$ & 0.1 & {$[81]$} \\
$\mathrm{Au} @ \mathrm{~PB}$ NP graphene & 0 & $100-126,400$ & 1.1 & This work \\
paper & 0 & $100-126,400$ & 0.5 & This work \\
rGO/PANI@Pt & & &
\end{tabular}



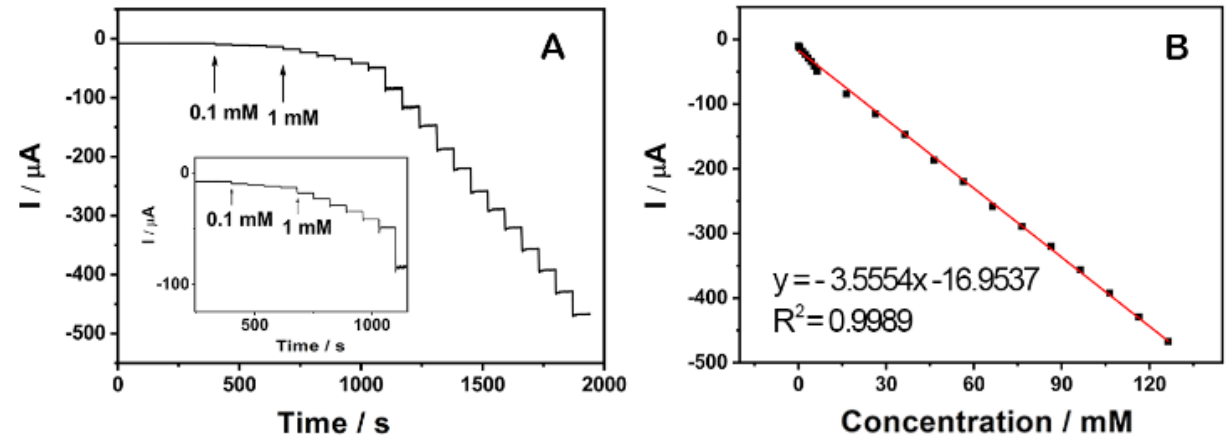

Figure 9. Typical steady-state response of the rGO/PANI@PtNi GCE to successive injection of $\mathrm{H}_{2} \mathrm{O}_{2}$ into the $\mathrm{N}_{2}$-saturated $0.2 \mathrm{M}$ PBS with $\mathrm{pH}=6.5$ at $0 \mathrm{~V}$. Inset: the amplified response curve at low concentrations (A); the corresponding calibration curve at $0 \mathrm{~V}(\mathbf{B})$.

Furthermore, the long-term stability of the rGO/PANI@PtNi modified electrode was also evaluated by carrying out the cyclic voltammogram under the same conditions after seven days (Figure S13). During the experiment, the used rGO/PANI@PtNi/GCE was preserved in air at room temperature. The cathodic peak current of this stored sample for seven days was found to have good stability only with a slight current decrease of $0.51 \%$, demonstrating the composite possessed not only a good electrochemical behavior for $\mathrm{H}_{2} \mathrm{O}_{2}$-detection but also sufficient environmental stability for long-term use.

\section{Conclusions}

In this paper, we fabricated a novel hierarchical rGO/PANI@PtNi nanocomposite with PtNi decorated PANI nano-spheres well stacked on the rGO sheet. Using water-stable PANI nano-sphere suspensions effectively inhibited the stacking of graphene sheets and the aggregation of nano-catalyst, leading to well size-controlled PtNi particles with quite a small diameter $(1.7 \pm 0.1 \mathrm{~nm})$. Moreover, the PANI nano-spheres on the rGO sheet generated a remarkably rougher surface compared to the composites without PANI, providing a large active surface area for both the electronic transfer and the anchoring of the precursor for the electrocatalysts. Consequently, rGO/PANI@PtNi/GCE exhibited conspicuous enhancement on the electronic conductivity by adding PANI. Importantly, rGO/PANI@PtNi/GCE also displayed high conductive and electrocatalytic properties for $\mathrm{H}_{2} \mathrm{O}_{2}$ detection. A linear dependence of the biosensor signals was detected from concentrations between $0.1 \mathrm{mM}$ and $126 \mathrm{mM}$, and the detection limit of the sensor was $0.5 \mu \mathrm{M}(\mathrm{S} / \mathrm{N}=3)$. In addition to the increased electro-conductivity, the promoted electrocatalytic property of $\mathrm{Pt}$ sites by the multi-valance $\mathrm{Ni}^{2+} \beta^{3+}$ in PtNi alloy was considered to be the other significant factor to upgrade the sensitivity for $\mathrm{H}_{2} \mathrm{O}_{2}$ decomposition. The synergic effect of the improved conductivity from PANI and rGO with a sophisticated structure and the promoted electrocatalytic property of PtNi alloy impart a high electrochemical sensitivity to rGO/PANI@PtNi/GCE and offer a promising approach for the development of the nonenzymatic sensors towards $\mathrm{H}_{2} \mathrm{O}_{2}$ detection.

Supplementary Materials: The following are available online at http://www.mdpi.com/2079-4991/9/8/1109/s1. Figure S1: TEM image of rGO, Figure S2: TEM images of platinum nanoparticles, Figure S3: TEM image of rGO/Pt nanocomposite, Figure S4: TEM image of rGO/PtNi nanocomposite, Figure S5: SEM of rGO/PANI@Pt nanocomposite, Figure S6: FT-IR spectrum of PANI, Figure S7: TEM and SEM images of rGO/PANI, Figure S8: Representative TEM images and the corresponding histograms of the particle size distribution of the PtNi metallic nanoparticles distributed on the surface of rGO/PtNi and rGO/PANI@PtNi, Figure S9: XPS Spectrum: wide survey spectra of the rGO/PANI@PtNi nanocomposite, Figure S10: XPS spectrum of Pt 4f from the rGO/PANI@Pt and rGO/PANI@PtNi composite, Figure S11: Cyclic voltammograms of rGO/PANI@PtNi/GCE in $\mathrm{N}_{2}$-saturated 0.2 $\mathrm{M}$ PBS at different $\mathrm{pH}$ value in the presence of $0.1 \mathrm{mM} \mathrm{H}_{2} \mathrm{O}_{2}$, Figure S12: Typical steady-state response of the rGO/PANI@Pt/GCE to successive injection of $\mathrm{H}_{2} \mathrm{O}_{2}$ and the corresponding calibration curve, Figure S13: CVs of pristine rGO/PANI@PtNi/GCE and the rGO/PANI@PtNi/GCE stored for 7 days. 
Author Contributions: Conceptualization, B.D. and F.-G.H.; formal analysis, F.-G.H.; investigation, B.D. and F.-G.H.; writing — original draft preparation, B.D. and F.-G.H.; writing—review and editing, B.D., F.J.S., A.K., G.S. and J.-Y.Y.; project administration, B.D. and F.J.S.; funding acquisition, B.D.

Funding: This research was funded by Shenzhen Fundamental Research Funds (JCYJ20170302145500980), Nature Science Foundation of Shenzhen University (2016001), Nanshan District Key Lab for Biopolymers and Safety Evaluation (No. KC2014ZDZJ0001A), and Shenzhen Sci \& Tech research grant (ZDSYS201507141105130) for financial support.

Acknowledgments: The authors also would like to sincerely thank the Instrumental Analysis Center of Shenzhen University (Xili Campus) for SEM and TEM. Special thanks go to the Materials and Device Testing Center of the Graduate School at Shenzhen, Tsinghua University for assistance with the XPS and HRTEM measurements.

Conflicts of Interest: The authors declare no conflict of interest.

\section{References}

1. Gómez-Plaza, E.; Cano-López, M. A review on micro-oxygenation of red wines: Claims, benefits and the underlying chemistry. Food Chem. 2011, 125, 1131-1140. [CrossRef]

2. Wang, J.; Sun, H.B.; Pan, H.Y.; Ding, Y.Y.; Wan, J.G.; Wang, G.H.; Han, M. Detection of hydrogen peroxide at a palladium nanoparticle-bilayer graphene hybrid-modified electrode. Sens. Actuators B Chem. 2016, 230, 690-696. [CrossRef]

3. Song, H.; Ni, Y.; Kokot, S. A novel electrochemical biosensor based on the hemin-graphene nano-sheets and gold nano-particles hybrid film for the analysis of hydrogen peroxide. Anal. Chim. Acta 2013, 788, 24-31. [CrossRef] [PubMed]

4. Niethammer, P.; Grabher, C.; Look, A.T.; Mitchison, T.J. A tissue-scale gradient of hydrogen peroxide mediates rapid wound detection in zebrafish. Nature 2009, 459, 996-999. [CrossRef] [PubMed]

5. Tian, Y.; Wang, F.; Liu, Y.; Pang, F.; Zhang, X. Green synthesis of silver nanoparticles on nitrogen-doped graphene for hydrogen peroxide detection. Electrochim. Acta 2014, 146, 646-653. [CrossRef]

6. Vinoth Kumar, J.; Karthik, R.; Chen, S.-M.; Raja, N.; Selvam, V.; Muthuraj, V. Evaluation of a new electrochemical sensor for selective detection of non-enzymatic hydrogen peroxide based on hierarchical nanostructures of zirconium molybdate. J. Colloid Interface Sci. 2017, 500, 44-53. [CrossRef] [PubMed]

7. Daemi, S.; Ghasemi, S.; Akbar Ashkarran, A. Electrospun CuO-ZnO nanohybrid: Tuning the nanostructure for improved amperometric detection of hydrogen peroxide as a non-enzymatic sensor. J. Colloid Interface Sci. 2019, 550, 180-189. [CrossRef] [PubMed]

8. Kuila, T.; Bose, S.; Khanra, P.; Mishra, A.K.; Kim, N.H.; Lee, J.H. Recent advances in graphene-based biosensors. Biosens. Bioelectron. 2011, 26, 4637-4648. [CrossRef] [PubMed]

9. Zamfir, L.G.; Rotariu, L.; Marinescu, V.E.; Simelane, X.T.; Baker, P.G.L.; Iwuoha, E.I.; Bala, C. Non-enzymatic polyamic acid sensors for hydrogen peroxide detection. Sens. Actuators B Chem. 2016, 226, 525-533. [CrossRef]

10. Chen, W.; Cai, S.; Ren, Q.Q.; Wen, W.; Zhao, Y.D. Recent advances in electrochemical sensing for hydrogen peroxide: A review. Analyst 2012, 137, 49-58. [CrossRef]

11. Zhou, J.; Min, M.; Liu, Y.; Tang, J.; Tang, W. Layered assembly of NiMn-layered double hydroxide on graphene oxide for enhanced non-enzymatic sugars and hydrogen peroxide detection. Sens. Actuators $B$ Chem. 2018, 260, 408-417. [CrossRef]

12. Wu, X.; Li, F.; Zhao, C.; Qian, X. One-step construction of hierarchical $\mathrm{Ni}(\mathrm{OH})_{2} / \mathrm{RGO} / \mathrm{Cu}_{2} \mathrm{O}$ on Cu foil for ultra-sensitive non-enzymatic glucose and hydrogen peroxide detection. Sens. Actuators B Chem. 2018, 274, 163-171. [CrossRef]

13. Salazar, P.; Rico, V.; González-Elipe, A.R. Non-enzymatic hydrogen peroxide detection at NiO nanoporous thin film- electrodes prepared by physical vapor deposition at oblique angles. Electrochim. Acta 2017, 235, 534-542. [CrossRef]

14. Dresselhaus, M.S.; Thomas, I.L. Alternative energy technologies. Nature 2001, 414, 332. [CrossRef] [PubMed]

15. Liu, Y.; Wu, H.H.; Li, M.; Yin, J.J.; Nie, Z.H. pH dependent catalytic activities of platinum nanoparticles with respect to the decomposition of hydrogen peroxide and scavenging of superoxide and singlet oxygen. Nanoscale 2014, 6, 11904-11910. [CrossRef] [PubMed] 
16. Li, Y.; Sella, C.; Lemaître, F.; Guille Collignon, M.; Thouin, L.; Amatore, C. Highly sensitive platinum-black coated platinum electrodes for electrochemical detection of hydrogen peroxide and nitrite in microchannel. Electroanalysis 2013, 25, 895-902. [CrossRef]

17. Liu, P.; Li, J.; Liu, X.; Li, M.; Lu, X. One-pot synthesis of highly dispersed PtAu nanoparticles-CTAB-graphene nanocomposites for nonenzyme hydrogen peroxide sensor. J. Electroanal. Chem. 2015, 751, 1-6. [CrossRef]

18. Mei, H.; Wu, W.Q.; Yu, B.B.; Wu, H.M.; Wang, S.F.; Xia, Q.H. Nonenzymatic electrochemical sensor based on Fe@Pt core-shell nanoparticles for hydrogen peroxide, glucose and formaldehyde. Sens. Actuators B Chem. 2016, 223, 68-75. [CrossRef]

19. Xu, C.; Wang, J.; Zhou, J. Nanoporous PtNi alloy as an electrochemical sensor for ethanol and $\mathrm{H}_{2} \mathrm{O}_{2}$. Sens. Actuators B Chem. 2013, 182, 408-415. [CrossRef]

20. Janyasupab, M.; Liu, C.W.; Zhang, Y.; Wang, K.W.; Liu, C.C. Bimetallic Pt-M (M = Cu, Ni, Pd, and Rh) nanoporous for $\mathrm{H}_{2} \mathrm{O}_{2}$ based amperometric biosensors. Sens. Actuators B Chem. 2013, 179, 209-214. [CrossRef]

21. Eda, G.; Chhowalla, M. Chemically derived graphene oxide: Towards large-area thin-film electronics and optoelectronics. Adv. Mater. 2010, 22, 2392-2415. [CrossRef] [PubMed]

22. Guo, S.; Wen, D.; Zhai, Y.; Dong, S.; Wang, E. Platinum nanoparticle ensemble-on-graphene hybrid nanosheet: One-pot, rapid synthesis, and used as new electrode material for electrochemical sensing. ACS Nano 2010, 4, 3959-3968. [CrossRef] [PubMed]

23. Zheng, W.; Hu, L.; Lee, L.Y.S.; Wong, K.Y. Copper nanoparticles/polyaniline/graphene composite as a highly sensitive electrochemical glucose sensor. J. Electroanal. Chem. 2016, 781, 155-160. [CrossRef]

24. Amanulla, B.; Palanisamy, S.; Chen, S.-M.; Velusamy, V.; Chiu, T.-W.; Chen, T.-W.; Ramaraj, S.K. A non-enzymatic amperometric hydrogen peroxide sensor based on iron nanoparticles decorated reduced graphene oxide nanocomposite. J. Colloid Interface Sci. 2017, 487, 370-377. [CrossRef] [PubMed]

25. Kumar, D.R.; Kesavan, S.; Baynosa, M.L.; Nguyen, V.Q.; Shim, J.-J. Flower-like $\mathrm{Bi}_{2} \mathrm{~S}_{3}$ nanostructures grown on nitrogen-doped reduced graphene oxide for electrochemical determination of hydrogen peroxide. J. Colloid Interface Sci. 2018, 530, 361-371. [CrossRef] [PubMed]

26. Wang, C.; Li, J.; Amatore, C.; Chen, Y.; Jiang, H.; Wang, X.-M. Gold nanoclusters and graphene nanocomposites for drug delivery and imaging of cancer cells. Angew. Chem. Int. Ed. 2011, 50, 11644-11648. [CrossRef]

27. Ning, L.; Guan, X.; Ma, J.; Wang, M.; Fan, X.; Zhang, G.; Zhang, F.; Peng, W.; Li, Y. A highly sensitive nonenzymatic $\mathrm{H}_{2} \mathrm{O}_{2}$ sensor based on platinum, $\mathrm{ZnFe}_{2} \mathrm{O}_{4}$ functionalized reduced graphene oxide. J. Alloys Comp. 2018, 738, 317-322. [CrossRef]

28. Liu, W.; Li, C.; Zhang, P.; Tang, L.; Gu, Y.; Zhang, Y.; Zhang, J.; Liu, Z.; Sun, G.; Zhang, Z. Hierarchical polystyrene@reduced graphene oxide-Pt core-shell microspheres for non-enzymatic detection of hydrogen peroxide. RSC Adv. 2015, 5, 73993-74002. [CrossRef]

29. Cao, X.; Halder, A.; Tang, Y.; Hou, C.; Wang, H.; Duus, J.Ø.; Chi, Q. Engineering two-dimensional layered nanomaterials for wearable biomedical sensors and power devices. Mater. Chem. Front. 2018, 2, 1944-1986. [CrossRef]

30. Hu, J.; Li, F.; Wang, K.; Han, D.; Zhang, Q.; Yuan, J.; Niu, L. One-step synthesis of graphene-AuNPs by HMTA and the electrocatalytical application for $\mathrm{O}_{2}$ and $\mathrm{H}_{2} \mathrm{O}_{2}$. Talanta 2012, 93, 345-349. [CrossRef]

31. Mayavan, S.; Jang, H.S.; Lee, M.J.; Choi, S.H.; Choi, S.M. Enhancing the catalytic activity of Pt nanoparticles using poly sodium styrene sulfonate stabilized graphene supports for methanol oxidation. J. Mater. Chem. A 2013, 1, 3489-3494. [CrossRef]

32. Zhang, Q.L.; Xu, T.Q.; Wei, J.; Chen, J.R.; Wang, A.J.; Feng, J.J. Facile synthesis of uniform Pt nanoparticles on polydopamine-reduced graphene oxide and their electrochemical sensing. Electrochim. Acta 2013, 112, 127-132. [CrossRef]

33. Namvari, M.; Du, L.; Stadler, F.J. Graphene oxide-based silsesquioxane-crosslinked networks-Synthesis and rheological behavior. RSC Adv. 2017, 7, 21531-21540. [CrossRef]

34. Du, L.; Namvari, M.; Stadler, F.J. Large amplitude oscillatory shear behavior of graphene derivative/polydimethylsiloxane nanocomposites. Rheologica Acta 2018, 57, 429-443. [CrossRef]

35. Qian, T.; Yu, C.; Zhou, X.; Wu, S.; Shen, J. Au nanoparticles decorated polypyrrole/reduced graphene oxide hybrid sheets for ultrasensitive dopamine detection. Sens. Actuators B Chem 2014, 193, 759-763. [CrossRef]

36. Stankovich, S.; Dikin, D.A.; Piner, R.D.; Kohlhaas, K.A.; Kleinhammes, A.; Jia, Y.; Wu, Y.; Nguyen, S.T.; Ruoff, R.S. Synthesis of graphene-based nanosheets via chemical reduction of exfoliated graphite oxide. Carbon 2007, 45, 1558-1565. [CrossRef] 
37. Guo, S.; Dong, S.; Wang, E. Three-dimensional Pt-on-Pd bimetallic nanodendrites supported on graphene nanosheet: Facile synthesis and used as an advanced nanoelectrocatalyst for methanol oxidation. ACS Nano 2010, 4, 547-555. [CrossRef]

38. Ghosh, P.; Chakrabarti, A.; Siddhanta, S.K. Studies on stable aqueous polyaniline prepared with the use of polyacrylamide as the water soluble support polymer. Eur. Polym. J. 1999, 35, 803-813. [CrossRef]

39. Chakraborty, M.; Mandal, B.M.; Mukherjee, D.C. Oxidative degradation of polyaniline during the chemical oxidative polymerization of aniline in aqueous methanol medium. Polym. Int. 2005, 54, 1158-1162. [CrossRef]

40. Mosquera, M.E.G.; Jamond, M.; Martinez-Alonso, A.; Tascon, J.M.D. Thermal transformations of kevlar aramid fibers during pyrolysis: Infrared and thermal analysis studies. Chem. Mater. 1994, 6, 1918-1924. [CrossRef]

41. Lee, Y.M.; Kim, J.H.; Kang, J.S.; Ha, S.Y. Annealing effects of dilute polyaniline/NMP solution. Macromolecules 2000, 33, 7431-7439. [CrossRef]

42. Yang, M.; Cao, K.; Sui, L.; Qi, Y.; Zhu, J.; Waas, A.; Arruda, E.M.; Kieffer, J.; Thouless, M.D.; Kotov, N.A. Dispersions of aramid nanofibers: A new nanoscale building block. ACS Nano 2011, 5, 6945-6954. [CrossRef]

43. Ramanathan, T.; Fisher, F.T.; Ruoff, R.S.; Brinson, L.C. Amino-functionalized carbon nanotubes for binding to polymers and biological systems. Chem. Mater. 2005, 17, 1290-1295. [CrossRef]

44. Villar-Rodil, S.; Paredes, J.I.; Martínez-Alonso, A.; Tascón, J.M.D. Atomic force microscopy and infrared spectroscopy studies of the thermal degradation of nomex aramid fibers. Chem. Mater. 2001, 13, 4297-4304. [CrossRef]

45. Shabbir, S.; Zulfiqar, S.; Shah, S.I.; Ahmad, Z.; Sarwar, M.I. Synthesis, morphology, and properties of self-assembled nanostructured aramid and polystyrene blends. J. Phys. Chem. B 2010, 114, 13241-13248. [CrossRef]

46. Stejskal, J. Protonation of polyaniline with 3-Nitro-1,2,4-triazol-5-one. Chem. Mater. 2002, 14, 3602-3606. [CrossRef]

47. An, J.; Liu, J.; Zhou, Y.; Zhao, H.; Ma, Y.; Li, M.; Yu, M.; Li, S. Polyaniline-grafted graphene hybrid with amide groups and its use in supercapacitors. J. Phys. Chem. C 2012, 116, 19699-19708. [CrossRef]

48. Stejskal, J. Brominated polyaniline. Chem. Mater. 2001, 13, 4083-4086. [CrossRef]

49. Kinyanjui, J.M.; Harris-Burr, R.; Wagner, J.G.; Wijeratne, N.R.; Hatchett, D.W. Hexachloroplatinate-initiated synthesis of polyaniline/platinum composite. Macromolecules 2004, 37, 8745-8753. [CrossRef]

50. Bernad, A.; Nieto, M.A.; Vioque, A.; Palaciáan, E. Modification of the amino and hydroxyl groups of lysozyme with carboxylic acid anhydrides: A comparative study. Biochim. et Biophys. Acta (BBA)-Protein Struct. Mol. Enzymol. 1986, 873, 350-355. [CrossRef]

51. Chen, Y.; Liang, Z.; Yang, F.; Liu, Y.; Chen, S. Ni-Pt core-shell nanoparticles as oxygen reduction electrocatalysts: Effect of Pt shell coverage. J. Phys. Chem. C 2011, 115, 24073-24079. [CrossRef]

52. Wu, J.; Qi, L.; You, H.; Gross, A.; Li, J.; Yang, H. Icosahedral platinum alloy nanocrystals with enhanced electrocatalytic activities. J. Am. Chem. Soc. 2012, 134, 11880-11883. [CrossRef]

53. Wu, J.; Zhang, J.; Peng, Z.; Yang, S.; Wagner, F.T.; Yang, H. Truncated octahedral Pt3Ni oxygen reduction reaction electrocatalysts. J. Am. Chem. Soc. 2010, 132, 4984-4985. [CrossRef]

54. Dang, T.T.; Pham, V.H.; Hur, S.H.; Kim, E.J.; Kong, B.-S.; Chung, J.S. Superior dispersion of highly reduced graphene oxide in N,N-dimethylformamide. J. Colloid Interface Sci. 2012, 376, 91-96. [CrossRef]

55. Yang, X.; Zhang, X.; Ma, Y.; Huang, Y.; Wang, Y.; Chen, Y. Superparamagnetic graphene oxide--Fe $\mathrm{O}_{4}$ nanoparticles hybrid for controlled targeted drug carriers. J. Mater. Chem. 2009, 19. [CrossRef]

56. Wang, G.-J.; Gao, Y.-Z.; Wang, Z.-B.; Du, C.-Y.; Wang, J.-J.; Yin, G.-P. Investigation of PtNi/C anode electrocatalysts for direct borohydride fuel cell. J. Power Sources 2010, 195, 185-189. [CrossRef]

57. Casella, I.G.; Guascito, M.R.; Sannazzaro, M.G. Voltammetric and XPS investigations of nickel hydroxide electrochemically dispersed on gold surface electrodes. J. Electroanal. Chem. 1999, 462, 202-210. [CrossRef]

58. Sun, Y.; Luo, M.; Qin, Y.; Zhu, S.; Li, Y.; Xu, N.; Meng, X.; Ren, Q.; Wang, L.; Guo, S. Atomic-thick PtNi nanowires assembled on graphene for high-sensitivity extracellular hydrogen peroxide sensors. ACS Appl. Mater. Interfaces 2017, 9, 34715-34721. [CrossRef]

59. Lee, E.; Jang, J.H.; Matin, M.A.; Kwon, Y.U. One-step sonochemical syntheses of Ni@Pt core-shell nanoparticles with controlled shape and shell thickness for fuel cell electrocatalyst. Ultrason. Sonochem. 2014, 21, 317-323. [CrossRef] 
60. Park, K.W.; Choi, J.H.; Kwon, B.K.; Lee, S.A.; Sung, Y.E.; Ha, H.Y.; Hong, S.A.; Kim, H.; Wieckowski, A. Chemical and electronic effects of $\mathrm{Ni}$ in $\mathrm{Pt} / \mathrm{Ni}$ and $\mathrm{Pt} / \mathrm{Ru} / \mathrm{Ni}$ alloy nanoparticles in methanol electrooxidation. J. Phys. Chem. B 2002, 106, 1869-1877. [CrossRef]

61. He, F.-G.; Du, B.; Sharma, G.; Stadler, F.J. Highly efficient polydopamine-coated poly(methyl methacrylate) nanofiber supported platinum-nickel bimetallic catalyst for formaldehyde oxidation at room temperature. Polymers 2019, 11, 674. [CrossRef]

62. Deivaraj, T.C.; Chen, W.; Lee, J.Y. Preparation of PtNi nanoparticles for the electrocatalytic oxidation of methanol. J. Mater. Chem. 2003, 13, 2555-2560. [CrossRef]

63. Kang, E.T.; Neoh, K.G.; Tan, K.L. Polyaniline: A polymer with many interesting intrinsic redox states. Prog. Polym. Sci. 1998, 23, 277-324. [CrossRef]

64. Zeng, J.; Gao, X.; Wei, W.; Zhai, X.; Yin, J.; Wu, L.; Liu, X.; Liu, K.; Gong, S. Fabrication of carbon nanotubes/poly(1,2-diaminobenzene) nanoporous composite via multipulse chronoamperometric electropolymerization process and its electrocatalytic property toward oxidation of NADH. Sens. Actuators $B$ Chem. 2007, 120, 595-602. [CrossRef]

65. Lu, D.; Zhang, Y.; Lin, S.; Wang, L.; Wang, C. Synthesis of PtAu bimetallic nanoparticles on graphene-carbon nanotube hybrid nanomaterials for nonenzymatic hydrogen peroxide sensor. Talanta 2013, 112, 111-116. [CrossRef]

66. Fang, Y.; Zhang, D.; Qin, X.; Miao, Z.; Takahashi, S.; Anzai, J.-I.; Chen, Q. A non-enzymatic hydrogen peroxide sensor based on poly(vinyl alcohol)-multiwalled carbon nanotubes-platinum nanoparticles hybrids modified glassy carbon electrode. Electrochim. Acta 2012, 70, 266-271. [CrossRef]

67. Katsounaros, I.; Schneider, W.B.; Meier, J.C.; Benedikt, U.; Biedermann, P.U.; Auer, A.A.; Mayrhofer, K.J.J. Hydrogen peroxide electrochemistry on platinum: Towards understanding the oxygen reduction reaction mechanism. Phys. Chem. Chem. Phys. 2012, 14, 7384-7391. [CrossRef]

68. Klaus, S.; Cai, Y.; Louie, M.W.; Trotochaud, L.; Bell, A.T. Effects of Fe electrolyte impurities on Ni(OH) $2 / \mathrm{NiOOH}$ structure and oxygen evolution activity. J. Phys. Chem. C 2015, 119, 7243-7254. [CrossRef]

69. Kong, F.Y.; Gu, S.X.; Li, W.W.; Chen, T.T.; Xu, Q.; Wang, W. A paper disk equipped with graphene/polyaniline/Au nanoparticles/glucose oxidase biocomposite modified screen-printed electrode: Toward whole blood glucose determination. Biosens. Bioelectron. 2014, 56, 77-82. [CrossRef]

70. Zhu, X.; Yuri, I.; Gan, X.; Suzuki, I.; Li, G. Electrochemical study of the effect of nano-zinc oxide on microperoxidase and its application to more sensitive hydrogen peroxide biosensor preparation. Biosens. Bioelectron. 2007, 22, 1600-1604. [CrossRef]

71. Xu, F.; Sun, Y.; Zhang, Y.; Shi, Y.; Wen, Z.; Li, Z. Graphene-Pt nanocomposite for nonenzymatic detection of hydrogen peroxide with enhanced sensitivity. Electrochem. Commun. 2011, 13, 1131-1134. [CrossRef]

72. Liu, F.; Xu, Q.; Huang, W.; Zhang, Z.; Xiang, G.; Zhang, C.; Liang, C.; Lian, H.; Peng, J. Green synthesis of porous graphene and its application for sensitive detection of hydrogen peroxide and 2,4-dichlorophenoxyacetic acid. Electrochim. Acta 2019, 295, 615-623. [CrossRef]

73. Sun, Y.; He, K.; Zhang, Z.; Zhou, A.; Duan, H. Real-time electrochemical detection of hydrogen peroxide secretion in live cells by $\mathrm{Pt}$ nanoparticles decorated graphene-carbon nanotube hybrid paper electrode. Biosens. Bioelectron. 2015, 68, 358-364. [CrossRef]

74. Song, R.-M.; Li, Z.-H.; Wei, P.-J.; Zhao, X.-L.; Chen, C.; Zhu, Z.-G. Flexible hydrogen peroxide sensors based on platinum modified free-standing reduced graphene oxide paper. Appl. Sci. 2018, 8, 848. [CrossRef]

75. Gabunada, J.C.; Vinothkannan, M.; Kim, D.H.; Kim, A.R.; Yoo, D.J. Magnetite nanorods stabilized by polyaniline/reduced graphene oxide as a sensing platform for selective and sensitive non-enzymatic hydrogen peroxide detection. Electroanalysis 2019. [CrossRef]

76. Bai, Z.; Dong, W.; Ren, Y.; Zhang, C.; Chen, Q. Preparation of nano Au and Pt alloy microspheres decorated with reduced graphene oxide for nonenzymatic hydrogen peroxide sensing. Langmuir 2018, 34, 2235-2244. [CrossRef]

77. Guler, M.; Turkoglu, V.; Bulut, A.; Zahmakiran, M. Electrochemical sensing of hydrogen peroxide using Pd@Ag bimetallic nanoparticles decorated functionalized reduced graphene oxide. Electrochim. Acta 2018, 263, 118-126. [CrossRef]

78. Lu, W.; Luo, Y.; Chang, G.; Sun, X. Synthesis of functional $\mathrm{SiO}_{2}$-coated graphene oxide nanosheets decorated with Ag nanoparticles for $\mathrm{H}_{2} \mathrm{O}_{2}$ and glucose detection. Biosens. Bioelectron. 2011, 26, 4791-4797. [CrossRef] 
79. Liu, J.; Yang, C.; Shang, Y.; Zhang, P.; Liu, J.; Zheng, J. Preparation of a nanocomposite material consisting of cuprous oxide, polyaniline and reduced graphene oxide, and its application to the electrochemical determination of hydrogen peroxide. Microchim. Acta 2018, 185, 172. [CrossRef]

80. Wang, L.W.E. A novel hydrogen peroxide sensor based on horseradish peroxidase immobilized on colloidal Au modified ITO electrode. Electrochem. Commun. 2004, 6, 225-229. [CrossRef]

81. Zhang, M.; Halder, A.; Hou, C.; Ulstrup, J.; Chi, Q. Free-standing and flexible graphene papers as disposable non-enzymatic electrochemical sensors. Bioelectrochemistry 2016, 109, 87-94. [CrossRef]

(C) 2019 by the authors. Licensee MDPI, Basel, Switzerland. This article is an open access article distributed under the terms and conditions of the Creative Commons Attribution (CC BY) license (http://creativecommons.org/licenses/by/4.0/). 